\title{
Understanding cognitive transport mode choice structures: means-ends chains as a type of second-order cybernetics
}

Tomaž Kolar

School of Economics and Business, University of Ljubljana, Ljubljana, Slovenia, and

Iztok Kolar

Faculty of Economics and Business, University of Maribor, Maribor, Slovenia
Received 11 March 2020 Revised 18 January 2021 Accepted 8February 2021

\begin{abstract}
Purpose - This paper aims to inform the promotion of sustainable modes of transport. For this purpose, it deploys a means-ends framework as a type of second-order cybernetics and uses it to explore cognitive transport mode choice structures.

Design/methodology/approach - The empirical study relies on a purposive sample and a qualitative research methodology known as laddering. It is aimed at the identification and comparative analysis of the cognitive means-ends structures of transport users.

Findings - The results reveal more positive and complex associations for the car than for public transport. Two main positive means-ends structures are identified for public transport, one related with the relaxation and the other with doing useful things while travelling. Dominant positive structures for the car are related with self-confidence, satisfaction and personal freedom. Negative means-ends structures in addition reveal important justifications and rationalizations for car use.

Practical implications - Based on the identified distinct means-ends elements and structures, this study holds important implications for developing a communications strategy and policy interventions seeking to promote public transport.

Originality/value - Means-ends theory is proposed as an integrative cybernetic framework for the study of stakeholders' (customers') mental models. The empirical study is the first to concurrently and comparatively examine positive and negative means-ends chains for the car and for the public transport modes.
\end{abstract}

Keywords Public transport, Second-order cybernetics, Laddering methodology, Means-ends theory, Private car, Mental models, Personal values

Paper type Research paper

\section{Introduction}

Cybernetics, as a management methodology for dealing with complex issues, can support environmental care and social responsibility initiatives (Mulej et al., 2013; Pejic Bach et al., 2019; Kennedy, 2011; Žižek and Mulej, 2013). Among others, this involves informed policymakers and the promotion of more sustainable modes of transport (Esget and

(C) Tomaž Kolar and Iztok Kolar. Published by Emerald Publishing Limited. This article is published under the Creative Commons Attribution (CC BY 4.0) license. Anyone may reproduce, distribute, translate and create derivative works of this article (for both commercial and non-commercial purposes), subject to full attribution to the original publication and authors. The full terms of this license may be seen at http://creativecommons.org/licences/by/4.0/legalcode second-order

cybernetics

(a)

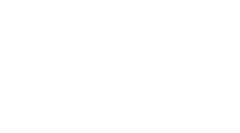


$\mathrm{K}$

51,2

828

Nordfjærn, 2019; Nordfjærn et al., 2016). To make car use less attractive and facilitate the use of public transport alternatives, policymakers need a deeper understanding of the reasons for choosing one mode of transport over another. This requires insights into how users evaluate travel mode alternatives and the factors that affect their decision-making. Here, despite extensive research, psychological factors are still unclear and exhibit significant research gaps (Chen et al., 2020; Chen and Chao, 2011; Beirão and Cabral, 2007; Ellaway et al., 2003; Hoffmann et al., 2020; Kaewkluengklom et al., 2017; Lanzini and Khan, 2017; Madigan et al., 2017; Mehdizadeh et al., 2019; Miletić et al., 2017; Nguyen-Phuoc et al., 2018).

Thus far, two contrasting approaches to the examination of transport mode choices are evident in the literature. The first is a "top-down" or attitudinal approach, which applies general psychological constructs and quantitatively verifies their predictive power. The second one is a "bottom-up" (exploratory) approach focused on identifying and examining discrete factors by means of qualitative approaches. Within the top-down approach, the theory of planned behaviour (TPB) is the most popular framework applied (Gardner and Abraham, 2008). It explains behaviour by means of attitudes, subjective norms and perceived behavioural control. To increase its explanatory power, this framework has been extended and combined with additional concepts and frameworks, including the technology acceptance model (TAM), value-belief-norm (VBN) theory and norm-activation-theory (Lanzini and Khan, 2017). While these extensions have improved the explanatory power held by the TPB framework, some relevant concepts such as personal goals and values still seem underexplored (Jakovcevic and Steg, 2013; Steg et al., 2014; Klöckner, 2013).

Representative bottom-up studies are, on the other hand, aimed at elicitation and a nuanced examination of specific travel mode factors. For instance, they have identified and categorized various (dis)advantages of car and public transport (Beirão and Cabral, 2007) and explored diverse reasons for reducing car use (Eriksson et al., 2008). The qualitative approach assures a more in-depth understanding of relevant factors that affect travel behaviour on the individual and structural levels (Nguyen-Phuoc et al., 2018; Ahern et al., 2017; Nakanishi and Black, 2016). It also shows that decisive factors may be transport-mode specific and that the same behavioural outcomes might be the result of "different underlying dynamics" (Eriksson et al., 2008; Ellaway et al., 2003; Collins and Chambers, 2005; Lo et al., 2013; Hoffmann et al., 2020). Yet, a bottom-up approach typically examines relevant factors in a fragmented and non-systemized manner.

The distinct (dis)advantages of the two approaches makes it beneficial to combine them. Here cybernetics provides a supportive research framework useful for the study of complex dynamic systems. It, namely, enhances systematic inquiry, reflectivity and epistemological pluralism (Ison et al., 2007; Pejic Bach et al., 2019). Given that transport users (customers) are the central agent in the transport system (Hysing, 2019), it is crucial that policymakers understand their reasoning model(s). These can be represented as cognitive means-ends structures and enable a better understanding of the self-reinforcing feedback effects in dynamic decision-making (Richardson and Andersen, 2010; Richardson et al., 1994). Accordingly, means-ends theory is proposed as an operative integrative framework for the study of customer judgement in complex systems such as transport.

Means-ends theory builds on the central tenet of "purposive reasoning" theories of human behaviour such as the TPB, namely, that human behaviour is intentional and guided by personal interests. According to means-ends theory, customers evaluate products in terms of their benefits, where a product's attributes serve as a means to some end - personal goals. These cognitive means-ends networks serve as the decision-making basis (Gutman, 1982; Peter and Olson, 1999). 
To date, no comprehensive study has considered how private (car) and public transport alternatives are perceived and compared in terms of means-ends chains. Therefore, the purpose of this paper is to comparatively explore these cognitive structures. More specifically, the following research goals are outlined:

- Identification of the (dis)advantages of car and public transport in terms of their distinct attributes.

- Identification and exploration of relevant personal values as 'ends' that affect the evaluation of car and public transport.

- Identification and exploration of means (benefits) and structures that link relevant attributes and personal values related to each transport mode choice.

- Comparison of the commonalities and differences between car and public transport in terms of their distinct means-ends structures.

To accomplish the stated purpose and research goals, the cybernetic underpinnings and logic of the means-ends framework are first presented and discussed in a literature review. Afterwards, the empirical study that deployed laddering methodology is explained, followed by a presentation and discussion of the results, managerial implications, limitations and conclusions.

\section{Literature review}

Cybernetics was initially defined as the "scientific study of control and communication in the animal and the machine" (Wiener, 1961). Today, it is applied to a diverse range of dynamic systems that include physical, cognitive and social systems. It aims to enhance understanding of the functions and processes of systems that have goals and include a feedback loop to dynamically adapt. In particular, cybernetics is interested in how autonomous learning systems process information and change their reactions (Kelly, 1994). Over time, new or second-order cybernetics evolved and developed less mechanistic and more reflexive approaches, implying that researchers consider responsibility for the (social) consequences of cybernetic systems (Krippendorff, 2008). Second-order cybernetics have thus moved towards an actor-oriented position and are today concerned with "understanding of understanding", where emphasis is on understanding actors' decisions and system "steering" (Geyer and van der Zouwen, 1986; von Foerster, 2003; Sweeting, 2015).

To model plural autonomous agents such as organizations, theories such as "mindset agency" have been proposed (Yolles and Fink, 2014). This theory postulates that social (super)systems consist of several subsystems, where cognitive and figurative subsystems provide mindscape structures, which dynamically steer the operative subsystem. Theories from the system dynamics domain consider similar "mindscape" structures, yet are also focused on individual agents. Here, the stakeholder approach was shown to be relevant for modelling social welfare initiatives (Pejic Bach et al., 2019; Kennedy, 2011; Richardson and Andersen, 2010). Although such initiatives require individual stakeholders to be engaged in the modelling process, they also need to understand a "collective" (aggregated) mental model of individual system users (customers), namely, the central agent in dynamic systems such as transport (Hysing, 2019).

The steering of dynamic social systems thus necessitates the involvement of a psychology with cybernetic foundations for dealing with the regulation of cognitive and affective systems and processes (Scott, 2011). It can further explain customer mental models and cognitive structures that guide their judgement and choices. In this sense, customer 
$\mathrm{K}$

51,2

830

decision-making can be conceived as a self-regulatory (mental) model where the higherorder goals determine the desired benefits and ultimately lead to product choice, while the subsequent purchase experience closes the feedback loop (Bagozzi and Dholakia, 1999; Paulssen and Bagozzi, 2005). Within such a hierarchically structured "valuation system", mental model specifies situation-specific means to desired ends (goals). It represents a possible (expected) "future states of the world" which the customer is motivated to approach or avoid (Uusberg et al., 2019). Mental models hence play a function of a "Brunswikean lens" through which individuals perceive available choices and enable stakeholders to better understand their decision-making (Richardson and Andersen, 2010).

Purposive mental models are comprehensively explained by means-ends theory. It suggests that customers buy products because of their benefits and personal meaning, which are provided by product attributes (Peter and Olson, 1999). For this sake, it is first important to identify relevant (distinctive) attributes and link them with the consumerrelevant benefits in a bottom-up manner. Such psychological benefits are in turn important because of their superordinate consequences or values, which is explicated as a means-end chain model (Gutman, 1982). Values play a guiding role in choice patterns, while different products exhibit different attribute/benefit/value constellations. Values are beliefs about some desirable end-states that transcend specific situations and affect and direct attitudes, preferences and behaviours in various domains (Chow and Amir, 2006; Vugt et al., 1995; Steg et al., 2014; Allen et al., 2002). Each product can thus be described as a bundle of attributes, but also as a bundle of more or less abstract benefits and final goals or values (Peter and Olson, 1999). Through these associative networks, means-end theory links products with customers and reveals why certain products and attributes are preferred (Botschen et al., 1999). In addition to the basic attribute-consequence-value (ACV) model, more complex models with more levels have also been proposed. A four-level model, for instance, consists of attributes, functional consequences, psychological consequences and values (Peter and Olson, 1999). Wilkie (1994) suggested a six-level model that makes further distinctions among attributes (physical and abstract) and values (instrumental and terminal). For the sake of parsimony and in line with the psychological ("Brunwikean lens") perspective taken, all factors in this study are considered as "perceived". They are categorized on three basic levels; namely, transport mode attributes, benefits (which encompass functional and psychological factors) and values (Peter and Olson, 1999; Grunert and Bech-Larsen, 2005).

Numerous studies that empirically examined diverse transport factors generally correspond with this simplified categorization. Identified "attribute" factors that influence transport choice include travel times, frequency of service, price, service performance and situational variables (Beirão and Cabral, 2007). Transport alternatives have also been associated not only with psychological "benefits" such as social status and selfdetermination (Nordfjærn et al., 2016) but also with affective and symbolic factors (Steg et al., 2014; Steg, 2005). When the psychosocial benefits of private vehicle and public transport use were compared, the car was found to provide greater psychosocial benefits (mastery, self-esteem, protection, prestige and feeling of autonomy) than public transport (Ellaway et al., 2003). Several studies also affirm the relevance of higher-order factors such as values, social norms and beliefs (Collins and Chambers, 2005; Eriksson and Forward, 2011; Jakovcevic and Steg, 2013; Steg and Vlek, 2009; Klöckner, 2013).

Still, the cognitive means-ends structures of transport users that encompass and relate these numerous factors on all three ACV levels have so far scarcely been examined. Namely, thus far only for cycling (Ho et al., 2015) and car-sharing, where Schaefers (2013) identified four motivational patterns (i.e. value-seeking, convenience, lifestyle and environmental 
motives). The lack of comparative exploration of the cognitive means-ends structures associated with the use of the car and public transport is thus evident and acted as the rationale for the present empirical study.

\section{Type of second-order cybernetics}

\section{Empirical study}

\subsection{Laddering methodology}

The elicitation of cognitive maps of individuals and aggregating them to create a common map can prove challenging for cybernetics (Cunha et al., 2016). This empirical study accordingly deployed a laddering technique, which is commonly used to examine meansends structures or ladders (Christensen and Olson, 2002; Reynolds and Gutman, 1988). The origins of the laddering technique relate to personal construct theory (Kelly, 1955), which postulates that people make sense of the world by arranging incoming stimuli into a set of hierarchically organized constructs. On this basis, Hinkle (1965) developed a method for the elicitation of "idiosyncratic constructs" that deploy a series of subsequent open-ended "why do you prefer a certain choice" questions, as essential for the laddering method.

Laddering evolved as an alternative method to "attitudinal" evaluation, which relies on scaling procedures and a set of predetermined items (e.g. Likert's scales) to measure "TPB" constructs (Ajzen, 2002). While laddering was originally developed as a qualitative ("soft") method, various "hard" approaches have also appeared that examine means-ends structures in a quantitative, survey-like manner (Phillips and Reynolds, 2009; ter Hofstede et al., 1998). One of these "hard" studies established that laddering increases explanatory power beyond conventional attitude measures (Grunert and Bech-Larsen, 2005).

A soft approach on the other hand allows laddering to be combined with other elicitation techniques, such as photo-elicitation, depending on the purpose and research goals (Bapiri et al., 2020). To date, laddering's applicability was demonstrated in diverse domains, such as information systems and technology use (Guo et al., 2012), services (Grünbaum, 2017; Kumar et al., 2020), mobile shopping (Park et al., 2019), management (Bourne and Jenkins, 2005), organizational culture (Rugg et al., 2002) and ethics (Park et al., 2018).

In the present study, laddering is deployed as a qualitative technique that entails interviews for an in-depth understanding of how consumers translate the attributes of products into meaningful associations with respect to self (Veludo-de-Oliveira et al., 2006). Uncovering these associations requires the identification of discrete ladder elements and their assignment to hierarchically structured categories, where several fundamental assumptions (conditions) should be met (Phillips and Reynolds, 2009). Ladders should, namely, be based on (derived from) meaningful choices (preference distinctions), respondents must be involved and carefully think about the personal relevance of each choice and collective responses must encompass all key levels of abstraction, techniques and analytical tools, such as in-depth interviews, coding matrix and graphical visualization of hierarchical means-end structures. For procedural purposes, different authors (ter Hofstede et al., 1998; Veludo-de-Oliveira et al., 2006) refer to three general steps that follow the detailed method description given in Reynolds and Gutman (1988):

(1) The first step in the data collection is the identification of attributes that refer to the perceived meaningful differences among competitive products. This may involve various 'probing' questions, which help participants reveal the attributes that distinguish among available product alternatives.

(2) In the second data collection step, one identifies attributes to serve as an input for the further in-depth interviews. Here, a series of "why is this attribute/benefit important for you" questions are asked, aimed at identifying expected 
$\mathrm{K}$

51,2

832

consequences (benefits), hence revealing the reasons that a particular attribute is desirable. For each attribute, interviews move up the ladder until a superordinate benefit or personal value is revealed.

(3) The third step covers the analysis of the contents elicited with the in-depth interviews. This requires coding and classification of the answers obtained into three basic categories, namely, attributes, benefits, personal values. This is performed by means of establishing connections between discrete pairs of identified elements and the frequency of their occurrences. Based on that, identified categorical elements are assigned to hierarchically structured ladders and depicted on a hierarchical value map, which visualizes the contents and links among the identified contents.

To successfully apply laddering, some additional recommendations are proposed, such as use of highly trained interviewers and homogeneous groups of respondents (Veludo-deOliveira et al., 2006). To avoid socially desirable answers and rationalize the use of a car instead of more sustainable and normatively warranted public transport, some other techniques are applied, which include negatively stated questions and negative chains (Reynolds and Gutman, 1988).

\subsection{Study background, data collection and sample}

The data were collected as part of a national project of the Ministry for Transport of Slovenia, partially funded with EU Cohesion Funds. Called "On the station" ("Na postaji"), the project was aimed at education and awareness about public transport. Car drivers were identified as one of the key target audiences of this project, for whom subsequent communication and education activities were planned that required adequate information inputs. For this purpose, a qualitative study was carried out by a regional market research agency Valicon, which did the sampling and provided experienced qualitative researchers. The data were collected by means of in-depth interviews, each lasting on average $45 \mathrm{~min}$. The sample consisted of 24 respondents, all of them being car users and all having access to public means of transport (within a distance of $500 \mathrm{~m}$ ), thereby being potential public transport users. Due to the exploratory purpose and qualitative nature, this sample size was considered adequate given that some comparable studies (Beirão and Cabral, 2007) used the same sample size, while relevant laddering studies have often deployed even smaller samples of relevant interviewees (Schaefers, 2013; Christensen and Olson, 2002). Half the respondents lived in cities (urban areas) and half in suburban areas. They were sampled for equal quotas in terms of gender and age (18-25, 26-40, 41-60 and 61-70). For the purpose of segment comparisons, employment status, location, and frequency of use of transport means were collected. For the personal in-depth interviews, a guide consisting of several topics was prepared. Besides introductory and demographic questions, there were questions on transport preferences and choice criteria (factors), environmental concerns and the "ideal" transport vehicle.

After the introductory questions, laddering interviews followed, aimed at identifying the key transport mode attributes, followed by a "Why is this important for you?" type of question. To help respondents identify or express their true opinions, additional probing questions were prepared following the "third person method" and negative laddering principle suggested by Anderson and Mirosa (2014). If more than one answer (e.g. more benefits) were provided on a particular level, ladders were built up to each of them. After completion of the in-depth interviews, the responses were coded and assigned to three basic aspects, namely, attributes, benefits or values. This revealed the frequency of the linkages 
between particular means-end chain elements and served as a basis for identifying the dominant chains and graphically presenting them.

\section{Results and discussion}

The introductory interview questions revealed the participants were less involved in use of and choosing between car and public transport. This appeared to be habitual behaviour where the first "by default" choice was the car ("I go to the car automatically and do not even think about alternatives"). Heavy and individual car use was especially notable for working people from suburban areas, who used a car for "most regular weekly trips". A car was more often shared by students, younger employees without children and younger retired people. All of them, nevertheless, considered a car as their first choice for bulk shopping, weekend trips and visits to friends and relatives. More intensive public transport (bus in particular) was used only by younger participants (students, if without a car) and some employees, who used it to commute to work (when work was in close proximity to home). A city bus was also used by retired people who lived in the city for afternoon/evening trips (because then there was no need to hurry). Participants who do not share a car with someone else rarely consider alternative means of transport. When they had, they usually looked at this issue from a time perspective; how much time did they have and how much were they willing to "sacrifice". The choice was then an "optimization" task since it depended on the number of stops, type(s) of trip(s), distances between destinations, costs and situational factors, such as the weather, "the loads to carry", etc. Only a few participants initially mentioned that in their day-to-day choice they paid attention to the ecological aspects of their transport. Thus, initial findings matched the studies, which suggested that transport mode choice depends on diverse demographic, lifestyle, situational, transport service-level and other relevant factors (Nordfjærn et al., 2016; Beirão and Cabral, 2007; Eriksson and Forward, 2011).

Analysis of the laddering interviews deepened the introductory findings. It encompassed two transport modes (private car and public transport) and examined the positive and negative means-ends structures of both; it yielded rich and complex findings. A detailed summary overview of the identified means-ends elements is presented in Table 1, where they are structured by hierarchical categories and valence. Structural connections for both transport means are visually depicted on hierarchical value maps, where positive and negative means-ends chains are presented for the car (Figures 1 and 2) and for public transport (Figures 3 and 4). To present a comprehensive, yet concise enough summary of the results, only elements that appeared with a frequency of 3 or more are presented on the value maps (i.e. the cut-off point is 3). Means-ends elements are named literally such that they closely resemble the participant-defined constructs and are presented as discretely as possible. If personal values were the result of diverse attribute-benefit chains, these (dominant) personal values (i.e. freedom, self-confidence and lack of calmness) were "split" into value maps to help more clearly present the participants' reasoning on why they were important. Some dominant value-chains are, thus, duplicated. In all cases, the dominant elements/chains are evident from the number of connections, where each connection on average had a frequency of 5-7. In addition, only a few less frequent elements and links (with a frequency of 3-4) were found and presented in the value maps where text is in italics and the connecting arrows are dotted.

For car use, there were 7 positive and 9 negative attributes identified, followed by 24 benefits and 16 car drawbacks, which, in turn, led to 9 positive and 3 negative personal values/losses. For public transport, there were 4 positive and 6 negative attributes found, followed by 12 benefits and 9 drawbacks, leading to 6 positive and 3 negative personal values/losses. This suggests the participants attached richer means-ends structures to the 
K

51,2

\section{4}

Table 1.

Means-ends elements identified

\begin{tabular}{|c|c|c|c|c|}
\hline & & Car & Pub & ic transport \\
\hline & Positive & Negative & Positive & Negative \\
\hline $\begin{array}{l}\text { Personal } \\
\text { values } \\
\text { (losses) }\end{array}$ & $\begin{array}{l}\text { - Freedom } \\
\text { - Relaxed } \\
\text { - Satisfaction } \\
\text { - Self-confidence } \\
\text { - Productivity } \\
\text { - Comfort } \\
\text { - Safety } \\
\text { - Happiness } \\
\text { - Financial } \\
\text { satisfaction }\end{array}$ & $\begin{array}{l}\text { - Lack of calmness } \\
\text { - Unsafe } \\
\text { - Health concerns }\end{array}$ & $\begin{array}{l}\text { - Relaxed } \\
\text { - Health and } \\
\text { Environment } \\
\text { - Satisfaction } \\
\text { - Safety } \\
\text { - Fun } \\
\text { - Productivity }\end{array}$ & $\begin{array}{l}\text { - Uncomfortable } \\
\text { - Unproductive } \\
\text { - Lack of calmness }\end{array}$ \\
\hline $\begin{array}{l}\text { Benefits } \\
\text { (drawbacks) }\end{array}$ & $\begin{array}{l}\text { - Independence } \\
\text { - Flexibility } \\
\text { - Unburdened } \\
\text { - Capable } \\
\text { - Less tired } \\
\text { - Time available } \\
\text { for other/more } \\
\text { things } \\
\text { - Planned } \\
\text { departure/arrival } \\
\text { - On-time (even } \\
\text { when late) } \\
\text { - Arrive faster } \\
\text { (save time) } \\
\text { - Later departure } \\
\text { - No walking } \\
\text { - Not tired } \\
\text { - Enjoying drive } \\
\text { - Feel useful } \\
\text { - Less tiresome } \\
\text { - Saving money } \\
\text { - No bags to } \\
\text { carry } \\
\text { - Things at hand } \\
\text { - No crowd } \\
\text { - Ambience } \\
\text { management } \\
\text { - Control drive } \\
\text { - Doing favour } \\
\text { - Socializing } \\
\text { - Sharing costs }\end{array}$ & $\begin{array}{l}\text { - Tiresome } \\
\text { - Stress } \\
\text { - Anger } \\
\text { - Less money for } \\
\text { other things } \\
\text { - Attention needed } \\
\text { - Costs (car) } \\
\text { - Demanding (time } \\
\text { and energy) } \\
\text { - Being late } \\
\text { - Danger } \\
\text { - Car malfunction } \\
\text { - Parking bills } \\
\text { - Parking search } \\
\text { - Confusing } \\
\text { - Threatening } \\
\text { - Waiting/queues } \\
\text { - Breathing bad air }\end{array}$ & $\begin{array}{l}\text { - More money } \\
\text { for other } \\
\text { expenses } \\
\text { - Save time and } \\
\text { energy } \\
\text { - Less pollution } \\
\text { - Doing nice } \\
\text { things } \\
\text { - Doing useful } \\
\text { things } \\
\text { - No parking } \\
\text { costs } \\
\text { - No parking } \\
\text { search } \\
\text { - Less traffic } \\
\text { - Meeting friends } \\
\text { - Less injuries } \\
\text { - No attention } \\
\text { needed }\end{array}$ & $\begin{array}{l}\text { - Physically demanding } \\
\text { - Anger } \\
\text { - Stress } \\
\text { - Time-consuming } \\
\text { - Expenses } \\
\text { - Waiting } \\
\text { - Slowness } \\
\text { - Need for taxi } \\
\text { - Cost (tickets) }\end{array}$ \\
\hline $\begin{array}{l}\text { Attributes } \\
\text { (dis/ } \\
\text { advantages) }\end{array}$ & $\begin{array}{l}\text { - No adjustments } \\
\text { - Own itinerary } \\
\text { - Drive faster } \\
\text { - Right on target } \\
\text { - Luggage space } \\
\text { - Own drive } \\
\text { - Can drive } \\
\text { others }\end{array}$ & $\begin{array}{l}\text { - Own drive } \\
\text { - Car responsibility } \\
\text { - High fuel costs } \\
\text { - Car maintenance } \\
\text { - Parking problems } \\
\text { - Impatient drivers } \\
\text { - Car accidents } \\
\text { - Congestions } \\
\text { - Pollution }\end{array}$ & $\begin{array}{l}\text { - No need for } \\
\text { parking } \\
\text { - More } \\
\text { passengers } \\
\text { - Bigger vehicle } \\
\text { - Other drive }\end{array}$ & $\begin{array}{l}\text { - Delays } \\
\text { - Infrequent schedules } \\
\text { - Walking (to station) } \\
\text { - Frequent stops } \\
\text { - Bad connections } \\
\text { - Transfers needed }\end{array}$ \\
\hline
\end{tabular}




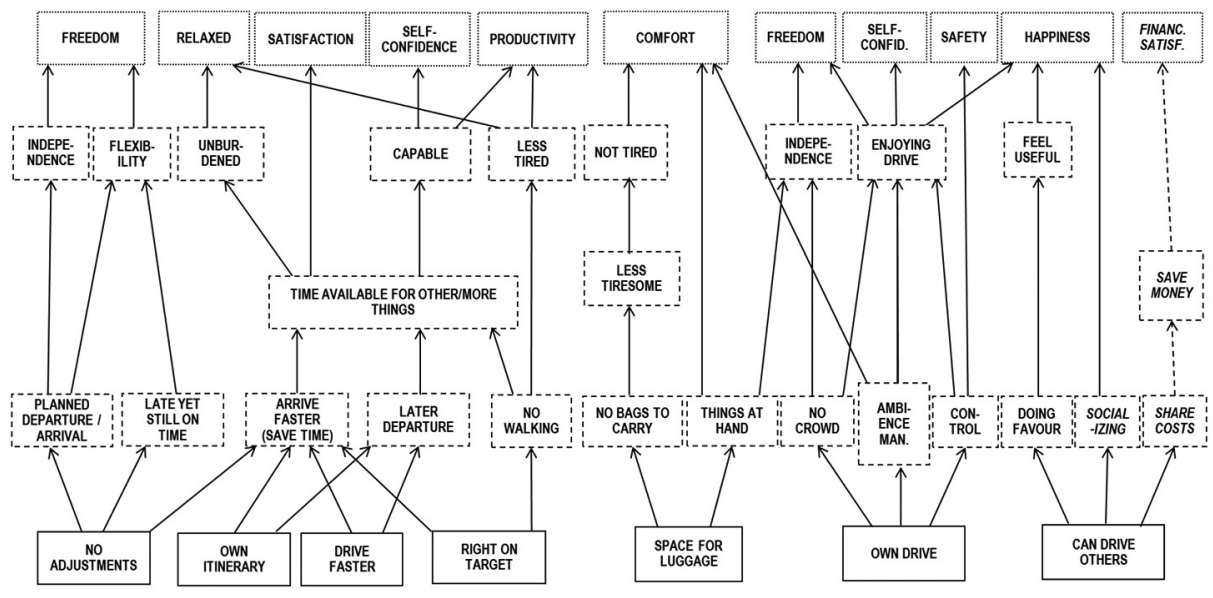

Type of
second-order
cybernetics

835

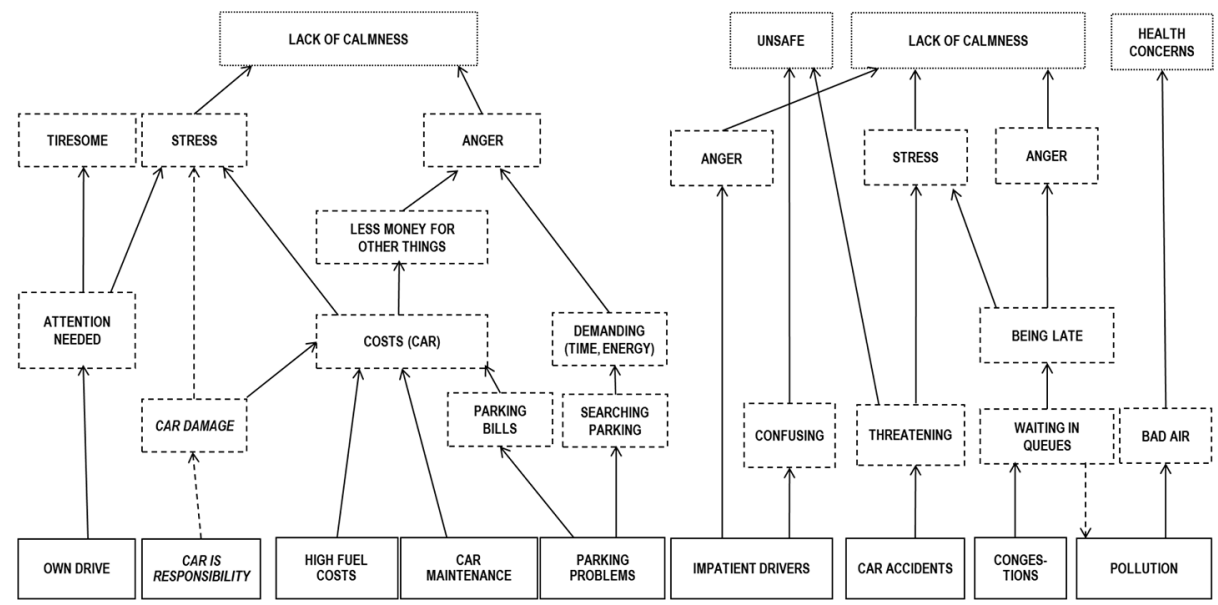

Figure 2.

Hierarchical value map for car negative elements

car than to public transport; in both instances, the positive structures had more elements than the negative ones. These richer means-ends structures for the car might reflect a more elaborated justification of the habitual behaviour. For this sake, it was interesting to deconstruct and compare the means-ends structures for both transport means.

Regarding car use, the identified positive attributes were most often related with car "ownership", the possibility of a faster drive, arriving right at the target but also the chances of other passengers joining. Interestingly, only a single attribute, that is space for luggage, explicitly referred to the vehicle itself, while others referred to the "car service". In this regard, a similar conclusion was reached by Schaefers (2013). These attributes ultimately lead to relevant personal values; the most important values are freedom, comfort, happiness and self-confidence. The dominant car means-end chains resulting from these personal values suggest the car provides freedom by means of independence, flexibility or joy in driving, which, in turn, result either from an independent itinerary, the possibility of 
K

51,2

836

Figure 3.

Hierarchical value map for public transport-positive elements

Figure 4.

Hierarchical value map for public transport-negative elements
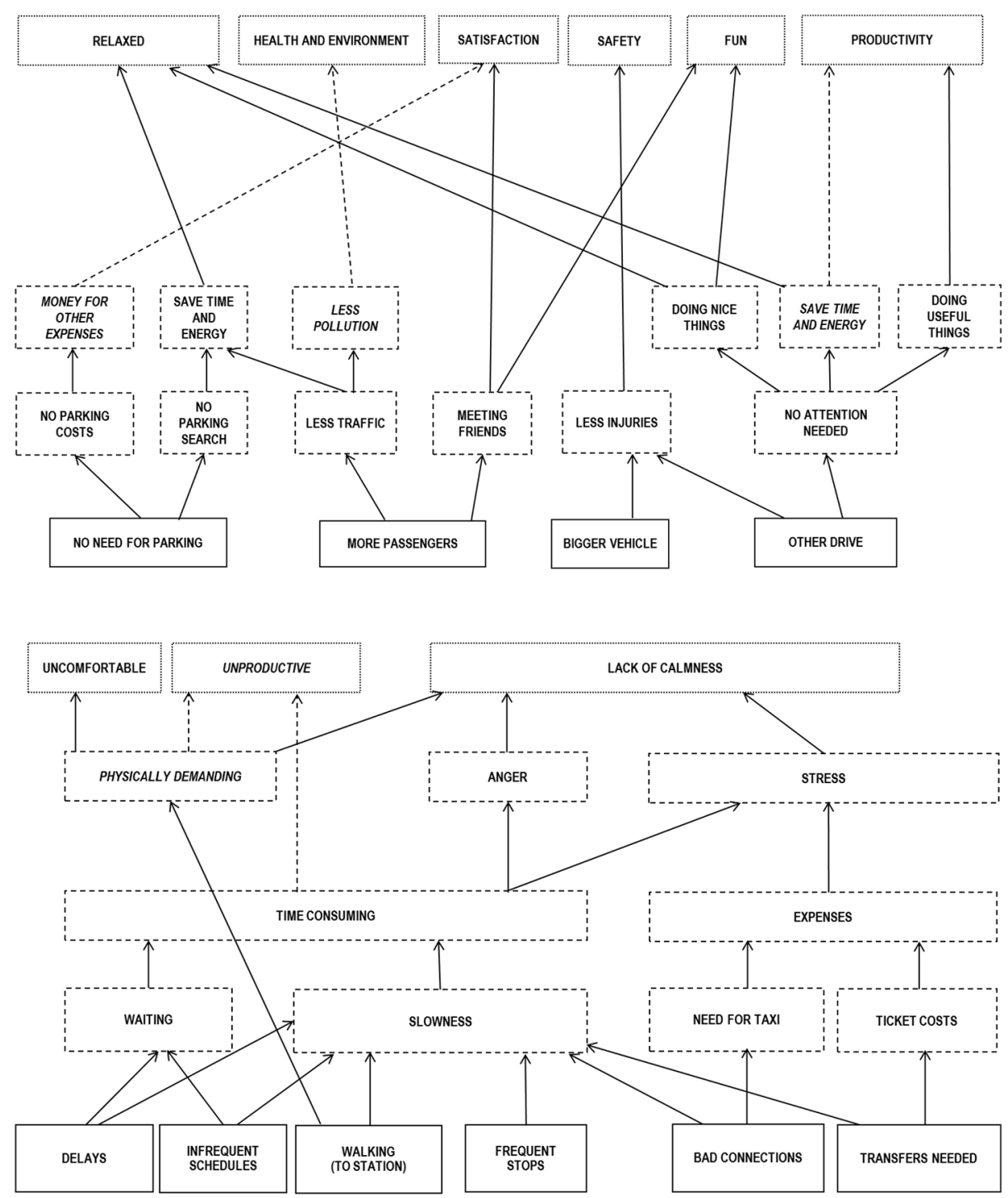

speeding-up while late, from having things at hand, avoiding crowds and ambience management (e.g. temperature, music, etc.). A car is a means for ensuring comfort, either due to time management and relief from psychological burdens or since a car drive is physically less demanding, creating a less tired user. Happiness results from a feeling of being useful due to doing favours for others, while productivity is a consequence of being less tired or the motivation that results from feeling more capable. Car use also provides self-confidence, either through a feeling of capability due to better time management, or sheer joy in driving that comes from managing a pleasant ambience. 
These findings are in many respects in line with previous studies, while some differences also exist. The identified attributes and psychological benefits, for instance, correspond with those described in Steg (2005), Ellaway et al. (2003) and Beirão and Cabral (2007). This, in particular, applies to the existence of instrumental benefits such as flexibility, independence, time efficiency, and (negative) affective factors such as anger and stress. However, some elements found in the present study were not indicated in previous studies, such as the attention needed as a drawback of the car and productivity as a personal value. In addition, the study by Gardner and Abraham (2008) indicates that optimization as a personal strategy is not only present with car use, but perhaps even more so while choosing between a car and public transport. The present study reveals several "negative" personal values (losses) not previously explored. Hence, it illuminates the role of the individual in explaining resistance and possible rationalizations in cases of "inappropriate" (e.g. unsustainable, unhealthy) behaviours (Nordfjærn et al., 2014; Chen and Chao, 2011; Anderson and Mirosa, 2014).

The positive means-end structures of car use depicted in Figure 1 were used as a reference for a comparison with the negative car means-ends (Figure 2) and a comparison with public transport (Figure 3 and 4). Negative attributes of car use most frequently lead to a highly dominant personal loss - (lack of) calmness, while the second, less frequent loss affected is (un)safety, followed by health concerns. Loss of calmness is largely due to the negative affective drawbacks of stress and anger caused by various "sacrifices" such as attention, time, energy and costs but also due to poor air quality. Still, personal values endangered by car use appear relatively "mild" in comparison to the positive ones. The participants did not perceive car use as a threat to their terminal personal values of relevance such as freedom, self-confidence and happiness. Pursuit of these personal goals seemed to more than outweigh the drawbacks of car use, which are manifold, yet less serious than the gains provided.

In summary, two broad themes underlie the positive view of the car as a transport alternative. The first is "instrumental" as it encompasses the efficient time and energy management. This theme suggests that the car is a good choice because of its functional benefits such as speed and time-saving, which make users productive and satisfied. The second theme is more "terminal", related to the "liberating" benefits of the car. These reveal that the car's key benefits are psychological and include independence, enjoyment in driving, socialization and a feeling of usefulness, which lead to self-confidence, happiness and a sense of freedom. Notably, the same personal values such as freedom and selfconfidence may result from different underlying benefits, where various functional and psychological factors are combined (mixed).

How did the participants perceive public transport compared to the car? In response to this question, they (approximately one-third) answered with fewer means-ends chain elements, which led to similarly, yet differently, structured personal values. As distinct public transport advantages over the car, they pointed out relatively few attributes, that also yielded fewer benefits and matched fewer personal goals. Two dominant means-ends chains depicted the reasoning about public transport. One led to being relaxed due to saving time and energy and due to the opportunity of doing pleasant things during the journey. The second dominant chain led to fun not only due to the possibility of meeting friends but also due to doing pleasant things. Fun was the only personal goal, which was specific to public transport and was not in any way related to car use. Satisfaction with public transport mostly resulted from socializing (meeting friends), which also affected fun while productivity was chiefly due to doing useful things. Health and environment were less prominent personal values for public transport and resulted in less pollution. 
$\mathrm{K}$

51,2

838

Public transport thus enabled the pursuit of similar, yet fewer personal values than the car, while more negative than positive attributes were indicated for public transport. These were caused by slowness, seen as time-consuming and physically demanding and, on the other hand, resulted in a need for additional means of transport, greater costs and negative affective consequences. Yet, the results show some specific and distinct benefits of public transport. There were, for instance, relatively fewer negative elements of public transport pointed out compared to the car. This suggests that car use holds more disadvantages and drawbacks than public transport. In this manner, the findings point out the comparative advantages of public transport. Besides fun, personal benefits that were public-transport-specific were useful and pleasant things to do, less pollution-causing, possibility of meeting friends and no attention required during the journey.

The results are in line with findings that general value orientations are related with the transport mode choice (Jakovcevic and Steg, 2013; Collins and Chambers, 2005; Vugt et al., 1995). Unlike broad value orientations that elicited (personal) values, the present study was user-defined and hence more specific. As such, they only partially match some universal value orientations, such as eco-centric/anthropocentric (Nordlund and Garvill, 2003). Still, they match some others, such as pro-self, hedonic and egoistic values (Vugt et al., 1995; Jakovcevic and Steg, 2013). Yet, the identified personal values (unsurprisingly) exhibit strongest correspondence with the values found in previous laddering studies (Ho et al., 2015; Schaefers, 2013).

However, more discrete and specific conceptions of values might exhibit better correspondence with the perceptual and behavioural aspects of transport-mode choice than universal value orientations. Thus, values were user-defined and hence closer to the actual personal goals of participants. This implication also applied to other psychological factors. Currently, general and universal (value, attitudinal, normative) factors are often regarded as determinants of travel-mode perception and choice. Yet, the amounts of explained variance of behavioural intentions and behaviours from these general factors are quite low (Klöckner, 2013). This might be due to the well-known problem of predicting specific behaviours from general dispositions (Ajzen and Fishbein, 1977). Their meta-analysis (Ajzen and Fishbein, 1977) on relatedness among attitudes and behaviours, namely, yielded no consistent conclusions regarding this relation. Still, they found that attitudes are good predictors of behaviours when specific elements of attitudes and behaviours (goals and activities, in particular) match. This supports the identification and examination of more specific, userdefined psychological factors to improve their relevance and explanatory power.

\section{Implications}

The findings improve understanding of transport users' mental models and hold important implications system "steering" and welfare interventions, (Pejic Bach et al., 2019; Richardson et al., 1994; Sweeting, 2015). More specifically, the findings inform policymakers and managers about the meaning of relevant "personal constructs", which is an important second-order cybernetic imperative (Löbler and Wloka, 2019). Such meaning is further specified by mental models where the identified means-ends structures reveal the users' hierarchical valuation system (Uusberg et al., 2019).

Established means-ends elements assist in the development of communication strategy (Reynolds and Craddock, 1988; Reynolds and Whitlark, 1995). For this purpose, the findings might be used to increase the appeal of public transport or, alternatively, the attractiveness of car use might be downplayed. For this purpose, the benefits and personal values identified for public transport or the negative corresponding elements and chains found for the car - might be used. Upon the development of a communication strategy, means-ends 
structures may be used for segmentation purposes and to complement (or replace) demographic and lifestyle segmentation criteria. Thus, the identified segments would be based on the "true", causal linkages between attributes, benefits, values and behaviours, rather than on single and descriptive segmentation criteria (Botschen et al., 1999). Identified segments can be later targeted with customized communications based on the dominant means-end chains identified, where the identified comparative advantages of public transport can be efficiently promoted. Despite this fact, car use is, for instance, found more important for achieving several personal goals and public transport holds some relative and distinctive advantages, which may be used for its effective (re)positioning. The most prominent personal values related to public transport are to relax, have fun and enhance productivity, where fun and environmental care are two personal values, which are not associated with the car. These are the most important and also the most distinguishing advantages of public transport. This is linked to more specific corresponding benefits and reveals why they are relevant and therefore suggests how they might be promoted.

In addition, there are several drawbacks to car use (i.e. attention needed, accidents, damage, worries, parking problems), which might be used to help downplay the appeal of car use. On top of promotion by means of advertising, interventions might aim at inducing purposeful considerations and planning intentions in the future (Eriksson et al., 2008). On the costs side, support for public transport is only viable when the marginal benefit of public transport is higher than the marginal cost of individual transport (Zefreh et al., 2017). More behavioural and contextual interventions, such as goal priming and habit-breaking, are also relevant (Légal et al., 2016; Lindenberg and Steg, 2007; Verplanken and Wood, 2006). Meansends findings are important for making improvements to transport offerings and services. Various means-ends elements can affect customers' satisfaction (Orsingher et al., 2011; Lai and Chen, 2011). Here, the established attributes that refer to service aspects (rather than the vehicle) are of prime relevance. In terms of suggesting strategy to promote public transport needs, we find that a strategy promoting public transport use must focus on the benefits, for example, relaxation, productivity, money and wording which one could use in such promotion might be: "using public transport is a cheap and pleasant way to save the world and your nerves".

During and after policy interventions, a means-ends framework might also be used for evaluation purposes. It was, for instance, found that the adoption of a means-ends framework led to better agency-client communication and more focused messages (BechLarsen, 2001). This could prove immensely important for public campaigns where a lack of common understanding of the campaign's objectives might impede its effectiveness. It is also of relevance to evaluate to which extent the messages communicated by advertising during campaigns actually correspond with the "mental" means-ends models of the target audience (Reynolds and Whitlark, 1995).

\section{Limitations and future research}

The presented study is subject to some limitations which largely arise from the qualitative research methodology used and should be considered in the interpretation of the results and implementation of the implications. While qualitative methods are advised for theory building in transport (Clifton and Handy, 2003), caution is advised when conceptual models (i.e. collective mental models) are generalized from a limited number of interviews. The present study also treated the examined benefits as a single broad category of "means", where there was no further systematic distinction between functional and psychological factors. Policy recommendations for these factors should therefore be considered with caution. Examination of further (i.e. objective) transport choice factors and/or interventions 
$\mathrm{K}$

51,2

840

by means of experimental methodology is thus warranted (Richardson et al., 1994; Verplanken and Wood, 2006). In addition, larger samples are also advised to improve generalizability (ter Hofstede et al., 1998). This would increase the possibility of validation and a more comprehensive examination of means-end chains on more detailed levels, such as functional and psychological consequences (Peter and Olson, 1999; Wilkie, 1994). The application of "hard" laddering might also include actual (rather than intended) user behaviours (Padel and Foster, 2005; Mirosa et al., 2013; Lai and Chen, 2011). These adjustments would allow for a comparison of how various factors predict actual transport behaviours and form suitable "behavioural" segments for policy interventions.

The current study was done on a purposeful sample that mainly took car users' perspective into account. It would be interesting to establish whether the means-ends chains differ for those users who primarily use public transport and for those who do not use a car. Public transport encompasses diverse modes, which might also differ substantively; thus, in the future it would be interesting to comparatively examine means-ends structures for specific public transport modes, such as bus, train, public bicycle systems and underground transport. More attention must be paid to the service and accessibility aspects, as cars might be used as a private mode or a public service-system, such as the car-sharing example suggests (Schaefers, 2013).

Laddering methodology also brings some inherent limitations such as "artificial" (rationalizing, socially desirable) answers that might be provided by some respondents. In addition to standard guidelines (Veludo-de-Oliveira et al., 2006), in the future this also welcomes alternative approaches to the examination of customer mental models, such as metaphor- and photo-elicitation (Christensen and Olson, 2002; Bapiri et al., 2020). These might alleviate the fact that uncovered hierarchical structures are to a certain extent artefacts of the laddering method. It also seems that laddering instils a positive bias on the transport mode use, which is also a possible limitation of the presented study. While the negative means-ends associations revealed possible barriers and rationalizations for using a car instead of public transport, it is possible that some barriers remain more "deeply buried". The purposeful, rational and logical assumptions of a means-ends framework, in combination with interrogative "why" questions, allow doubt that some (more emotional, unconscious, self-defence) mechanisms remain undisclosed by the laddering methodology. For the purpose of uncovering such reasons and factors and so as to better illuminate how users justify morally or normatively inappropriate behaviours, the use of additional, projective techniques is advised (Strutton et al., 1994). In this manner, second-order cybernetics alongside new disciplines, frameworks and methods might distinctively enhance the modelling and steering of complex and dynamic social systems such as transport.

\section{References}

Ahern, S.M., Arnott, B., Chatterton, T., de Nazelle, A., Kellar, I. and McEachan, R.R. (2017), "Understanding parents' school travel choices: a qualitative study using the theoretical domains framework", Journal of Transport and Health, Vol. 4, pp. 278-293.

Ajzen, I. (2002), "Constructing a TPB questionnaire: conceptual and methodological considerations", pp. 1-14, available at: www.semanticscholar.org/paper/Constructing-a-TpB-Questionnaire\%3AConceptual-and-Ajzen/6074b33b529ea56c175095872fa40798f8141867?p2df

Ajzen, I. and Fishbein, M. (1977), "Attitude-behavior relations: a theoretical analysis and review of empirical research”, Psychological Bulletin, Vol. 84 No. 5, pp. 888-918.

Allen, M.W., Hung Ng, S. and Wilson, M. (2002), "A functional approach to instrumental and terminal values and the value-attitude-behaviour system of consumer choice", European Journal of Marketing, Vol. 36 Nos 1/2, pp. 111-135. 
Anderson, K. and Mirosa, M. (2014), "Revealing barriers to healthier fast food consumption choices", British Food Journal, Vol. 116 No. 5, pp. 821-831.

Bagozzi, R.P. and Dholakia, U. (1999), "Goal setting and goal striving in consumer behaviour”, Journal of Marketing, Vol. 63 No. 4_suppl1, pp. 19-32.

Bapiri, J., Esfandiar, K. and Seyfi, S. (2020), "A photo-elicitation study of the meanings of a cultural heritage site experience: a means-end chain approach", Journal of Heritage Tourism, Vol. 16 No. 1, pp. 1-17, doi: 10.1080/1743873X.2020.1756833.

Bech-Larsen, T. (2001), "Model-based development and testing of advertising messages: a comparative study of two campaign proposals based on the MECCAS model and a conventional approach", International Journal of Advertising, Vol. 20 No. 4, pp. 499-519.

Beirão, G. and Cabral, J.S. (2007), "Understanding attitudes towards public transport and private car: a qualitative study", Transport Policy, Vol. 14 No. 6, pp. 478-489.

Botschen, G., Thelen, E.M. and Pieters, R. (1999), "Using means-end structures for benefit segmentation: an application to services", European Journal of Marketing, Vol. 33 Nos 1/2, pp. 38-58.

Bourne, H. and Jenkins, M. (2005), "Eliciting managers' personal values: an adaptation of the laddering interview method", Organizational Research Methods, Vol. 8 No. 4, pp. 410-428.

Chen, C.F. and Chao, W.H. (2011), "Habitual or reasoned? Using the theory of planned behavior, technology acceptance model, and habit to examine switching intentions toward public transit", Transportation Research Part F: Traffic Psychology and Behaviour, Vol. 14 No. 2, pp. 128-137.

Chen, J., Chen, Q. and Li, H.P. (2020), "Psychological influences on bus travel mode choice: a comparative analysis between two Chinese cities", Journal of Advanced Transportation, Vol. 2020, pp. 1-9, doi: 10.1155/2020/8848741.

Chow, S. and Amir, S. (2006), "The universality of values: implications for global advertising strategy", Journal of Advertising Research, Vol. 46 No. 3, pp. 301-314.

Christensen, G.L. and Olson, J.C. (2002), "Mapping consumers' mental models with ZMET”, Psychology and Marketing, Vol. 19 No. 6, pp. 477-501.

Clifton, K.J. and Handy, S.L. (2003), "Qualitative methods in travel behaviour research", in Jones, P. and Stopher, P.R. (Eds), Transport Survey Quality and Innovation, Emerald Group Publishing, pp. 283-302, doi: 10.1108/9781786359551-016.

Collins, C.M. and Chambers, S.M. (2005), "Psychological and situational influences on commutertransport-mode choice", Environment and Behavior, Vol. 37 No. 5, pp. 640-661.

Cunha, A.A.R., Silva Filho, J.L. and Morais, D.C. (2016), "Aggregation cognitive maps procedure for group decision analysis”, Kybernetes, Vol. 45 No. 4, pp. 589-603, doi: 10.1108/K-04-2015-0092.

Ellaway, A., Macintyre, S., Hiscock, R. and Kearns, A. (2003), "In the driving seat: psychosocial benefits from private motor vehicle transport compared to public transport", Transportation Research Part F: Traffic Psychology and Behaviour, Vol. 6 No. 3, pp. 217-231.

Eriksson, L. and Forward, S.E. (2011), "Is the intention to travel in a pro-environmental manner and the intention to use the car determined by different factors?", Transportation Research Part D: Transport and Environment, Vol. 16 No. 5, pp. 372-376.

Eriksson, L., Friman, M. and Gärling, T. (2008), "Stated reasons for reducing work-commute by car", Transportation Research Part F: Traffic Psychology and Behaviour, Vol. 11 No. 6, pp. 427-433.

Esget, K.S. and Nordfjærn, T. (2019), "The role of transport priorities, transport attitudes and situational factors for sustainable transport mode use in wintertime", Transportation Research Part F: Traffic Psychology and Behaviour, Vol. 62 (April), pp. 473-482.

Gardner, B. and Abraham, C. (2008), "Psychological correlates of car use: a meta-analysis", Transportation Research Part F: Traffic Psychology and Behaviour, Vol. 11 No. 4, pp. 300-311.

Geyer, F. and van der Zouwen, J. (1986), Sociocybernetic Paradoxes: observation, Control and Evolution of Self-Steering Systems, Sage, Beverly Hills, CA. 
$\mathrm{K}$

51,2

842

Grünbaum, N.N. (2017), “The laddering method in service innovation research”, in Sørensen, F. (Ed.), Research Methods in Service Innovation, Edward Elgar Publishing, Cheltenham.

Grunert, K.G. and Bech-Larsen, T. (2005), "explaining choice option attractiveness by beliefs elicited by the laddering method", Journal of Economic Psychology, Vol. 26 No. 2, pp. 223-241.

Guo, Z., Li, Y. and Stevens, K.J. (2012), "Analyzing students' technology use motivations: an interpretive structural modeling approach", Communications of the Association for Information Systems, Vol. 30 No. 14, pp. 199-224, doi: 10.17705/1CAIS.03014.

Gutman, J. (1982), "A means-end chain model based on consumer categorization processes", Journal of Marketing, Vol. 46 No. 2, pp. 60-72.

Hinkle, D. (1965), "The change of personal constructs from the viewpoint of a theory of implications", $\mathrm{PhD}$ dissertation, Ohio State University, Columbus, $\mathrm{OH}$.

Ho, C.I., Liao, T.Y., Huang, S.C. and Chen, H.M. (2015), "Beyond environmental concerns: using meansend chains to explore the personal psychological values and motivations of leisure/recreational cyclists", Journal of Sustainable Tourism, Vol. 23 No. 2, pp. 234-254.

Hoffmann, C., Abraham, C., White, M.P. and Skippon, S.M. (2020), "Ambivalent about travel mode choice? A qualitative investigation of car user and non-car user attitudes", Transportation Research Part A: Policy and Practice, Vol. 141, pp. 323-338.

Hysing, E. (2019), "Responsibilization: the case of road safety governance”, Regulation and Governance, Wiley Online Library, doi: 10.1111/rego.12288, pp. 1-14.

Ison, R., Blackmore, C., Collins, K. and Furniss, P. (2007), "Systemic environmental decision making: designing learning systems", Kybernetes, Vol. 36 Nos 9/10, pp. 1340-1361, doi: 10.1108/ 03684920710827346.

Jakovcevic, A. and Steg, L. (2013), "Sustainable transportation in Argentina: values, beliefs, norms and car use reduction", Transportation Research Part F: Traffic Psychology and Behaviour, Vol. 20, pp. 70-79.

Kaewkluengklom, R., Satiennam, W., Jaensirisak, S. and Satiennam, T. (2017), "Influence of psychological factors on mode choice behaviour: case study of BRT in Khon Kaen City, Thailand", Transportation Research Procedia, Vol. 25, pp. 5072-5082.

Kelly, G.A. (1955), A Theory of Personality - the Psychology of Personal Constructs, Norton, New York, NY.

Kelly, K. (1994), Out of Control: The New Biology of Machines, Social Systems and the Economic World, Addison-Wesley, Boston, MA.

Kennedy, M. (2011), "Cybernetics and system dynamics: impacts on public policy”, Kybernetes, Vol. 40 Nos 1/2, pp. 124-140, doi: 10.1108/03684921111117960.

Klöckner, C.A. (2013), "A comprehensive model of the psychology of environmental behaviour - a Meta-analysis”, Global Environmental Change, Vol. 23 No. 5, pp. 1028-1038.

Krippendorff, K. (2008), "Cybernetics's reflexive turns”, Cybernetics and Human Knowing, Vol. 15 Nos 3/4, pp. 173-184, available at: http://repository.upenn.edu/asc_papers/136

Kumar, P., Follen, M., Huang, C.C. and Cathey, A. (2020), "Using laddering interviews and hierarchical value mapping to gain insights into improving patient experience in the hospital: a systematic literature review", Journal of Patient Experience, Vol. 7 No. 6, pp. 1-8, doi: 10.1177/ 2374373520942425.

Lai, W.T. and Chen, C.F. (2011), "Behavioral intentions of public transit passengers - the roles of service quality, perceived value, satisfaction and involvement”, Transport Policy, Vol. 18 No. 2, pp. 318-325.

Lanzini, P. and Khan, S.A. (2017), "Shedding light on the psychological and behavioral determinants of travel mode choice: a meta-analysis", Transportation Research Part F: Traffic Psychology and Behaviour, Vol. 48, pp. 13-27. 
Légal, J.B., Meyer, T., Csillik, A. and Nicolas, P.A. (2016), “Goal priming, public transportation habit and travel mode selection: the moderating role of trait mindfulness", Transportation Research Part F: Traffic Psychology and Behaviour, Vol. 38, pp. 47-54.

Lindenberg, S. and Steg, L. (2007), "Normative, gain and hedonic goal frames guiding environmental behaviour", Journal of Social Issues, Vol. 63 No. 1, pp. 117-137.

Lo, S.H., van Breukelen, G.J., Peters, G.J.Y. and Kok, G. (2013), "Proenvironmental travel behavior among office workers: a qualitative study of individual and organizational determinants", Transportation Research Part A: Policy and Practice, Vol. 56, pp. 11-22.

Löbler, H. and Wloka, M. (2019), "Customers' everyday understanding of 'value' from a second-order cybernetic perspective”, Journal of Marketing Management, Vol. 35 Nos 11/12, pp. 992-1014.

Madigan, R., Louw, T., Wilbrink, M., Schieben, A. and Merat, N. (2017), "What influences the decision to use automated public transport? Using UTAUT to understand public acceptance of automated road transport systems", Transportation Research Part F: Traffic Psychology and Behaviour, Vol. 50, pp. 55-64.

Mehdizadeh, M., Zavareh, M.F. and Nordfjaern, T. (2019), "Mono-and multimodal green transport use on university trips during winter and summer: hybrid choice models on the norm-activation theory”, Transportation Research Part A: Policy and Practice, Vol. 130, pp. 317-332.

Miletić, G.-M., Gašparović, S. and Carić, T. (2017), "Analysis of socio-spatial differentiation in transport mode choice preferences”, Promet - Traffic\& Transportation, Vol. 29 No. 2, pp. 233-242.

Mirosa, M., Lawson, R. and Gnoth, D. (2013), "Linking personal values to energy-efficient behaviors in the home", Environment and Behavior, Vol. 45 No. 4, pp. 455-475.

Mulej, M., Božičnik, S., Čančer, V., Hrast, A., Jurše, K., Kajzer, Š., Knez-Riedl, J., Jere Lazanski, T., Mlakar, T., Mulej, N., Potočan, V., Risopoulos, F., Rosi, B., Steiner, G., Štrukelj, T., Uršič, D. and Ženko, Z. (2013), Dialectical Systems Thinking and the Law of Requisite Holism concerning Innovation, Emergent Publications, Goodyear, AZ.

Nakanishi, H. and Black, J.A. (2016), "Travel habit creation of the elderly and the transition to sustainable transport: exploratory research based on a retrospective survey", International Journal of Sustainable Transportation, Vol. 10 No. 7, pp. 604-616.

Nguyen-Phuoc, D.Q., Currie, G., De Gruyter, C. and Young, W. (2018), "How do public transport users adjust their travel behaviour if public transport ceases? A qualitative study", Transportation Research Part F: Traffic Psychology and Behaviour, Vol. 54, pp. 1-14.

Nordfjærn, T., Simsekoglu, Ö. and Rundmo, T. (2016), "Active transport, public transport and electric car as perceived alternatives in a motorized Norwegian sample”, Transportation Research Part F: Traffic Psychology and Behaviour, Vol. 42, pp. 70-79.

Nordfjærn, T., Simsekoglu, Ö. and Rundmo, T. (2014), "The role of deliberate planning, car habit and resistance to change in public transportation mode use", Transportation Research Part D: Transport and Environment, Vol. 27, Part A, pp. 90-98.

Nordlund, A.M. and Garvill, J. (2003), "Effects of values, problem awareness, and personal norm on willingness to reduce personal car use", Journal of Environmental Psychology, Vol. 23 No. 4, pp. 339-347.

Orsingher, C., Marzocchi, G.L. and Valentini, S. (2011), "Consumer (goal) satisfaction: a means-ends chain approach”, Psychology and Marketing, Vol. 28 No. 7, pp. 730-748.

Padel, S. and Foster, C. (2005), "Exploring the gap between attitudes and behaviour: understanding why consumers buy or do not buy organic food", British Food Journal, Vol. 107 No. 8, pp. 606-625.

Park, H., Vandekerckhove, W., Lee, J. and Jeong, J. (2018), "Laddered motivations of external whistleblowers: the truth about attributes, consequences, and values", Journal of Business Ethics, Vol. 165 No. 4, pp. 565-578, doi: 10.1007/s10551-018-4082-0.

Park, H.E., Yap, S.F.C. and Makkar, M. (2019), "A laddering study of motivational complexities in mobile shopping”, Marketing Intelligence and Planning, Vol. 37 No. 2, pp. 182-196. 
$\mathrm{K}$

51,2

844

Paulssen, M. and Bagozzi, R.P. (2005), "A self-regulatory model of consideration set formation”, Psychology and Marketing, Vol. 22 No. 10, pp. 785-812.

Pejic Bach, M., Tustanovski, E., Ip, A.W., Yung, K.L. and Roblek, V. (2019), "System dynamics models for the simulation of sustainable urban development: a review and analysis and the stakeholder perspective", Kybernetes, Vol. 49 No. 2, pp. 460-504, doi: 10.1108/K-04-2018-0210.

Peter, P.J. and Olson, J.C. (1999), Consumer Behavior and Marketing Strategy, 6th ed., McGraw-Hill, Boston, MA.

Phillips, J.M. and Reynolds, T.J. (2009), "A hard look at hard laddering", Qualitative Market Research: An International Journal, Vol. 12 No. 1, pp. 83-99, doi: 10.1108/13522750910927232.

Reynolds, T.J. and Craddock, A.B. (1988), "The application of the MECCAS model to the development and assessment of advertising strategy: a case study", Journal of Advertising Research, April/ May, pp. 43-54.

Reynolds, T.J. and Gutman, J. (1988), “Laddering theory, method, analysis, and interpretation”, Journal of Advertising Research, Vol. 28 No. 1, pp. 11-31.

Reynolds, T.J. and Whitlark, D.B. (1995), "Applying laddering data to communications strategy and advertising practice", Journal of Advertising Research, July/August, pp. 9-17.

Richardson, G.P. and Andersen, D.F. (2010), "Stakeholder dynamics", Proceedings 28th International Conference of the System Dynamics Society, pp. 1-19, available at: https://proceedings. systemdynamics.org/2010/proceed/papers/P1255.pdf

Richardson, G.P., Andersen, D.F., Maxwell, T.A. and Stewart, T.R. (1994), "Foundations of mental model research", Proceedings of the 1994 International System Dynamics Conference, pp. 181-192, available at: www.albany.edu/ gpr/MentalModels.pdf

Rugg, G., Eva, M., Mahmood, A., Rehman, N., Andrews, S. and Davies, S. (2002), "Eliciting information about organizational culture via laddering”, Information Systems Journal, Vol. 12 No. 3, pp. 215-229.

Schaefers, T. (2013), "Exploring carsharing usage motives: a hierarchical means-end chain analysis", Transportation Research Part A: Policy and Practice, Vol. 47, pp. 69-77.

Scott, B. (2011), "Toward a cybernetic psychology", Kybernetes, Vol. 40 Nos 9/10, pp. 1247-1257, doi: $10.1108 / 03684921111169369$.

Steg, L. (2005), "Car use: lust and must. Instrumental, symbolic and affective motives for car use", Transportation Research Part A: Policy and Practice, Vol. 39 Nos 2/3, pp. 147-162.

Steg, L. and Vlek, C. (2009), "Encouraging pro-environmental behaviour: an integrative review and research agenda", Journal of Environmental Psychology, Vol. 29 No. 3, pp. 309-317.

Steg, L., Perlaviciute, G., Van der Werff, E. and Urvink, J. (2014), “The significance of hedonic values for environmentally relevant attitudes, preferences, and actions", Environment and Behavior, Vol. 46 No. 2, pp. 163-192.

Strutton, D., Vitell, S.J. and Pelton, L.E. (1994), "How consumers may justify inappropriate behavior in market settings: an application on the techniques of neutralization", Journal of Business Research, Vol. 30 No. 3, pp. 253-260.

Sweeting, B. (2015), “Cybernetics of practice”, Kybernetes, Vol. 44 Nos 8/9, pp. 1397-1405, doi: 10.1108/ K-11-2014-0239.

ter Hofstede, F., Audenaert, A., Steenkamp, J.B.E. and Wedel, M. (1998), "An investigation into the association pattern technique as a quantitative approach to measuring means-end chains", International Journal of Research in Marketing, Vol. 15 No. 1, pp. 37-50.

Uusberg, A., Suri, G., Dweck, C. and Gross, J.J. (2019), "Motivation: a valuation systems perspective", in Maital, N. and Haas, I.J. (Eds), Emotion in the Mind and Body, Springer, Cham, pp. 161-192, available at: www.researchgate.net/profile/Andero_Uusberg/publication/336702272_Motiva tion_A_Valuation_Systems_Perspective/links/5dd863ef299bf10c5a2a87a8/Motivation-A-Valua tion-Systems-Perspective.pdf 
Veludo-de-Oliveira, T.M., Akemi Ikeda, A. and Cortez Campomar, M. (2006), "Laddering in the practice of marketing research: barriers and solutions", Qualitative Market Research: An International Journal, Vol. 9 No. 3, pp. 297-306.

Verplanken, B. and Wood, W. (2006), "Interventions to break and create consumer habits", Journal of Public Policy and Marketing, Vol. 25 No. 1, pp. 90-103.

von Foerster, H. (2003), Understanding: Essays on Cybernetics and Cognition, Springer-Verlag, New York, NY.

Vugt, M., Meertens, R.M. and Lange, P.A. (1995), "Car versus public transportation? The role of social value orientations in a real-life social dilemma", Journal of Applied Social Psychology, Vol. 25 No. 3, pp. 258-278.

Wiener, N. (1961), Cybernetics or Control and Communication in the Animal and the Machine, MIT Press, Cambridge, MA.

Wilkie, W.L. (1994), Consumer Behavior, 3rd ed., John Wiley and Sons, New York, NY.

Yolles, M. and Fink, G. (2014), "Personality, pathology and mindsets: part 1-agency, personality and mindscapes”, Kybernetes, Vol. 43 No. 1, pp. 92-112, doi: 10.1108/K-01-2013-0011.

Zefreh, M.M., Meszaros, F., Junevičius, R. and Torok, A. (2017), "Economic investigation of a public transport support policy: a case study at Budapest", Promet - Traffic \& Transportation, Vol. 29 No. 1, pp. 77-84, available at: https://raffic.fpz.hr/index.php/PROMTT/article/view/2072 (accessed 14 September 2019).

Žižek, S.Š. and Mulej, M. (2013), "Social responsibility: a way of requisite holism of humans and their well-being", Kybernetes, Vol. 42 No. 2, pp. 318-335.

\section{Corresponding author}

Iztok Kolar can be contacted at: iztok.kolar@um.si

For instructions on how to order reprints of this article, please visit our website: 